OPTIMUM. STUDIA EKONOMICZNE NR 6 (48) 2015

Damian S. PYRKOSZ1

DOI: 10.15290/ose.2015.06.78.04

\title{
COOPERATION, CULTURE AND SHARED VALUES - POLAND AND ITS NEIGHBOURHOOD
}

\begin{abstract}
Summary
The aim of the paper is the idea of cooperation as an undervalued element of the system of market economy. The system has been dominated by competition despite the wishes of its founding father, Adam Smith. Several other authors have also pointed to the fact and proposed to focus more on cooperation in order to keep economy in balance with society. Excessive reliance on the competition hurt people's relationships and undermined their place in the economic system. The significance of cooperation rises when combined with the idea of culture and shared values. Chosen methods of assessing values as related to economic development are mentioned. The World Values Survey (WVS) results are used to assess the proximity of the values of the neighbouring countries of Poland. Despite changes in the composition of the values in Poland and the countries, the analysis shows that a great deal of these values are common which may potentially enhance potential international cooperation among these countries.
\end{abstract}

Key words: cooperation, competition, culture, shared values, relationships, market economy

\section{Methodology}

The paper is an analysis of a primarily qualitative character, although it uses elements of descriptive analysis to present its key argument which is the significance of cooperation in the system of market economy. The article is informally divided in two parts: theoretical and practical. The former consists primarily of a review of the socioeconomic literature on the notion of competition and cooperation, and their role in the market with a special emphasis placed on the latter. It commences with a reference to Adam Smith ideas on competition and cooperation deriving from his most monumental works to argue that the Father of Economics stressed the two concepts' complementariness rather than subordination of any. This argument is replicated by a number of much more recent authors, that among those referred to in the text are inter alia Polanyi [1944], Soros [1997], Brandenburger and Nalebuff [1996], Axelrod and Hamilton [1981]. Then, with reference to Hofstede [1991], Trompenaars and Hampden-Turner [1998] and Inglehart and Welzel [2015] the paper goes on to explore the significance of the idea of shared values as the elements of the socio-economic system which sanction

\footnotetext{
${ }^{1}$ Dr Damian S. Pyrkosz - Wydział Ekonomii, Uniwersytet Rzeszowski, e-mail: daspy@univ.rzeszow.pl
} 
complementariness of competition and cooperation. The empirical part of the paper is built on the analysis of values by Inglehart and Welzel [2015] and the data of the World Values Survey (WVS). The WVS information is used to account for similarities in values in the population of Poland and its neighboring countries. Then tracing the values changes across subsequent waves of the WVS provides information on processes taking place in the societies. Eventually, the WVS data is used to make an observation referring to the populations attitudes to the idea competition. The paper ends with conclusions regarding the role of shared values in the context of enhancing cooperation as necessary elements of the market economy.

\section{Competition - the essence of the market}

Market economy relies on competition. This seemingly uncontroversial statement is supported by both economists and politicians, producers and consumers in the past and present. Competition is thus identified as the key trait of capitalism. According to the Collins English Dictionary, 'capitalism' is an economic system based on the private ownership of the means of production, distribution, and exchange, characterized by the freedom of capitalists to operate or manage their property for profit in competitive conditions. Competition thus provides an avenue for continuous testing, experimenting and adapting in reaction to changing conditions [Boaz, 2011, p.31]. Moreover, it helps businesses deliver the best possible product to consumers in response to their expectation of the same. Competition provides incentives to improve our lives, both in and outside the markets, and helps to make the best use of people's self-interest.

It was Adam Smith who first explained how competition, aided by division of labor, involuntarily changes self-interest into the common good. It is not from the benevolence of the butcher, the brewer, or the baker that we expect our dinner, but from their regard to their own interest [Smith, 1776, pp.9-10]. Competition further enhances public good as ...by directing that industry in such a manner as its produce may be of the greatest value, he intends only his own gain, and he is in this, as in many other cases, led by an invisible hand to promote an end which was no part of his intention [Smith, 1776, p. 293]. Thus, in the market economy self-interest generates behavior that benefits others, yet at the same time competition serves as a check on it by restraining producer's attempt to take advantage of their customers. For this, competition in its essence is the sole regulator of the market which should be devoid of any other restrictions.

\section{Cooperation - the undervalued twin brother}

Despite all the virtues, the market's excessive reliance on competition has earned it a reputation of an economic system that is a rate-race, cut-throat, dog-eat-dog or else survival of the fittest or even it has given rise to emporiophobia [Rubin 2014; Boaz 2011]. In this light a number of scientists and business people [inter alia Axelrod, Hamilton 1981; Boaz 2011; Taylor 2015; Soros 1997; Branderburger, Nalebuff 1996; Nowak 2012; Ims, Jakobsen 2010; Deutsch 2011; Tyler 2011; Patchell 1996; Rubin 2014] observe that we could all 
gain more if we emphasized and focused on the cooperative side of the market to a greater extent. Quite representative in this respect is an observance that market should rather be perceived as a place where competition [...] happens as a series of gemuinely cooperative decisions, every time a buyer and seller come together in a mutually agreed-upon and voluntarily made transaction [Taylor, 2015]. The complementary relationship between competition and cooperation in the market economy was also postulated by Adam Smith in the first place. In his another work published nearly two decades before the seminal Wealth of Nations, The Theory of Moral Sentiments, for the first time he actually used the term the invisible band to express the effect of self-interest and competition in producing a result parallel to cooperation. They are led by an invisible hand to make nearly the same distribution of the necessaries of life, which would have been made, had the earth been divided into equal portions among all its inbabitants, and thus without intending it, without knowing it, advance the interest of the society [Smith 1759 p. 215]. Smith is a father of both competitive and cooperative analyses [Rubin $2014]^{2}$.

The role of cooperation as the essence of society and economy was emphasized early on in the twentieth century. The idea that a human being is primarily a social construct pursuing cooperation, prestige and enhancement of social capital was advocated by Polanyi [1944]. Relationships and cooperation between people are the essence of both society and economy:[...] man's economy, as a rule, is submerged in his social relationships. He does not act so as to safeguard his individual interest in the possession of material goods; he acts so as to safeguard his social standing, his social claims, his social assets. He values material goods only in so far as they serve this end. [Polanyi 1944 p. 48]. He pointed out that all economic systems, beside the market one, rely on cooperation:

- symmetry guided by the principle of reciprocity which denotes reciprocal exchange of goods and services between members of society and economic system;

- centricity organized according to redistribution where trade and production are focused on the central entity (e.g. tribal leader) and then redistributed on to members of society;

- autarchy following householding where production is focused on individual household production (e.g. self-reliant families in the remote rural areas).

None of the above economic systems relied on competition; the prevalent cooperation was conducive to the preservation of the social fabric and fostered social relationships. Markets provided only an extra opportunity for the exchange of goods not obtainable otherwise. In this arrangement economy is an element of society - it is embedded in society - and thus subordinated to religion, politics and social relations It is society which controls economy, not vice versa. The introduction of market economy, which followed the Industrial Revolution, reversed the relationship between society and economic system and meant [...] running of society as an adjunct to the market. Instead of economy being embedded in social relations, social relations are embedded in the economic system [ibid. p. 60]. Excessive

2 The Theory of Moral Sentiments published in 1759 was meant to be an integral part of Smith's published nearly twenty years later bestseller. He himself regarded the former as more significant and it was where the author for the first time referred to the invisible hand - the idea of self-interest being transformer by competition into common good, or else the self-interest-competition relationship. For further explanation on the contradictory roles of man and self-interest see Smith [1998]. 
reliance on competition, and forgoing cooperation, undermined social ties, endangered civilizational development, atomized societies, and left people virtually defenseless in the face of lack of guidance from governments and cultural institutions. Ultimately, it was accountable for a series of cataclysms like the two World Wars, the Great Depression, and the rise of fascism.

The idea that cooperation is intrinsically intertwined with competition in the market was advocated by several authors more recently. The mutual relationship of cooperation and competition should be observed as [...] cooperation is as much a part of the system as competition, and the slogan "survival of the fittest" distorts this fact [Soros 1997]. Moreover, there is a need for balance between the two as [...] too much competition and too little cooperation can cause intolerable inequities and instability [ibid.] The intrinsic mutual reliance between cooperation and competition should rather be seen as complementary. This kind of thinking about competition and cooperation was strongly supported by the seminal book by Brandenburger and Nalebuff [1996] under a tell-telling title Co-opetition. The fact that companies establish (or at least hope to) continuing and lasting relationships and communication with their customers (they benefit when customers provide them with truthful feedback on their goods and services) and their suppliers and help them implement innovative solutions proves that competition cannot do without a great deal of cooperation.

It is certainly true that [...]throughout the market system individuals and firms compete to cooperate better [Boaz, 2011, p. 531]. On the other hand, cooperation surpasses competition in terms of benefits to various system participants. Empirically proven research results (based on prisoner's dilemma) led to a conclusion that cooperation:

- can get started in a predominantly noncooperative world, when based on reciprocity;

- can thrive in variegated environment;

- provides stability and can defend itself once fully established [Axelrod, Hamilton, 1981, p. 1395].

The key message that the study conveys is that in real life situations, when market participants react with each other on a frequent and regular basis, the winning strategy is cooperation, not competition. Yet it would be certainly more practical if we could acknowledge the fact that [...] cooperation is as much a part of capitalism as competition [Boaz 2011]. They are not polar opposites [Taylor 2015]. Markets should be perceived as a vast cooperative venture in which buyers and sellers work together to determine prices and allocate resources [Voss, 2012]. After all, market transactions are possible only under the condition of cooperation, not coercion.

\section{The significance of shared values and culture}

The idea that makes it possible for the both above elements to complement each other and establish the economic system of market implicitly assumes a presence of a common pool of values shared by its participants. The co-existence and mutual dependency of competition and cooperation derives from the fact that both are essential 
elements of the basic system of shared values like natural liberty [Boaz 2011], democracy, the rule of law, and respect for others, to cite just the most universal ones. Although, traditionally the notions of culture and values have been excluded from economic analysis, especially with regard to their contribution to economic development, the late twentieth century saw a revival of interest in the culture and value-focused interpretation of economic development [Banfield, 1958; Fukuyama, 1995; Harrison, Huntington, 2000; Hofstede, 1991; Landes, 1998; North, 1990; Putnam, 1993; Trompenaars, HampdenTurner, 1998 $]^{3}$. What is more important, culture, shared values, norms and worldview (i.e. perception of the world around) enhance cooperation and mutual coordination with the world around [Wimmer, 2013] as opposed to the lack of such interactions which hinder cooperation [Coleman, 1990]. Shared values become particularly important with regard to regional development and innovation spillovers/processes. They make a critical socio-cultural pool of interdependencies in the form of developed routines, shared norms and trust that facilitate (or inhibit) interactive processes and mutual understanding in the transmission of information and knowledge [Fischer, 2002, p. 25]. These seemingly nonproductive ideas, i.e. shared social values, interact with the productive economic sphere and affect the long-run economic development. They become crucial for economy to grow [Kima, Lee, 2015].

\section{Sharing values among countries}

The idea of shared values has attracted a great deal of attention for various practical reasons ${ }^{4}$. Generally, several models have been created to demonstrate the role people's beliefs and values play in economic development. Hofstede [1991] distinguished and analyzed shared values in different cultures along five dimensions: power distance, individualism vs. collectivism, masculinity vs. femininity, uncertainty avoidance, and long- vs. short-term orientation. An alternative model was proposed by Trompenaars and Hampden-Turner [1998] It was based on a matrix of seven cultural factors (shared values) to account for the discrepancies determined along the criteria of universalism vs. particularism, analyzing vs. integrating, individualism vs. communitarianism, inner- vs. outer-directedness, time as sequence vs. time as synchronization, achieved vs. ascribed status, and equality vs. hierarchy. Although the two frameworks differed, they shared the same basic objective, i.e. to understand how people in different value-sharing cultures behave and perceive their economic and social development.

The most advanced and systematic analysis of shared values and beliefs and their impact on the level of economic, social, political and civic development has been performed by Inglehart and Welzel [2015] and used the data of the World Values

${ }^{3}$ For reasons of the breach between culture and economics refer to Guiso, Sapienza, Zingales [2006], Boulding [1972] and Wilkin [1997].

${ }^{4}$ One of the most recent-yet less relevant to this study, Creating shared value (CSV), is the idea that the competitiveness of a company and the health of the communities around it are mutually dependent. Understanding and taking advantage of the relationships between societal and economic progress can potentially contribute to global development and redefine capitalism [Porter, Kramer 2011]. 
Survey. Their analysis demonstrates two major dimensions of cross-cultural discrepancy in the world built along two continua between traditional and secular-rational values on the one hand, and survival and self-expression values on the other:

- traditional values are those which stress religion, family ties and values and, respect for authority. Consequently, divorce, abortion, euthanasia and suicide are not approved of by members of these societies who also tend to demonstrate nationalistic worldviews;

- secular-rational values place emphasis on the opposite preferences compared to traditional values. Hence, religion, traditional family values and authority are less revered; on the other hand divorce, abortion, euthanasia and suicide are considered moderately acceptable;

- survival values draw attention to economic and physical security. This worldview tends accept a relatively ethnocentric outlook and low levels of trust and tolerance;

- self-expression values give precedence of environmental protection, growing tolerance of foreigners, gays and lesbians and gender equality over any other values. An important feature of this set of values is support for participation in decision-making in economic and political life.

PICTURE 1.

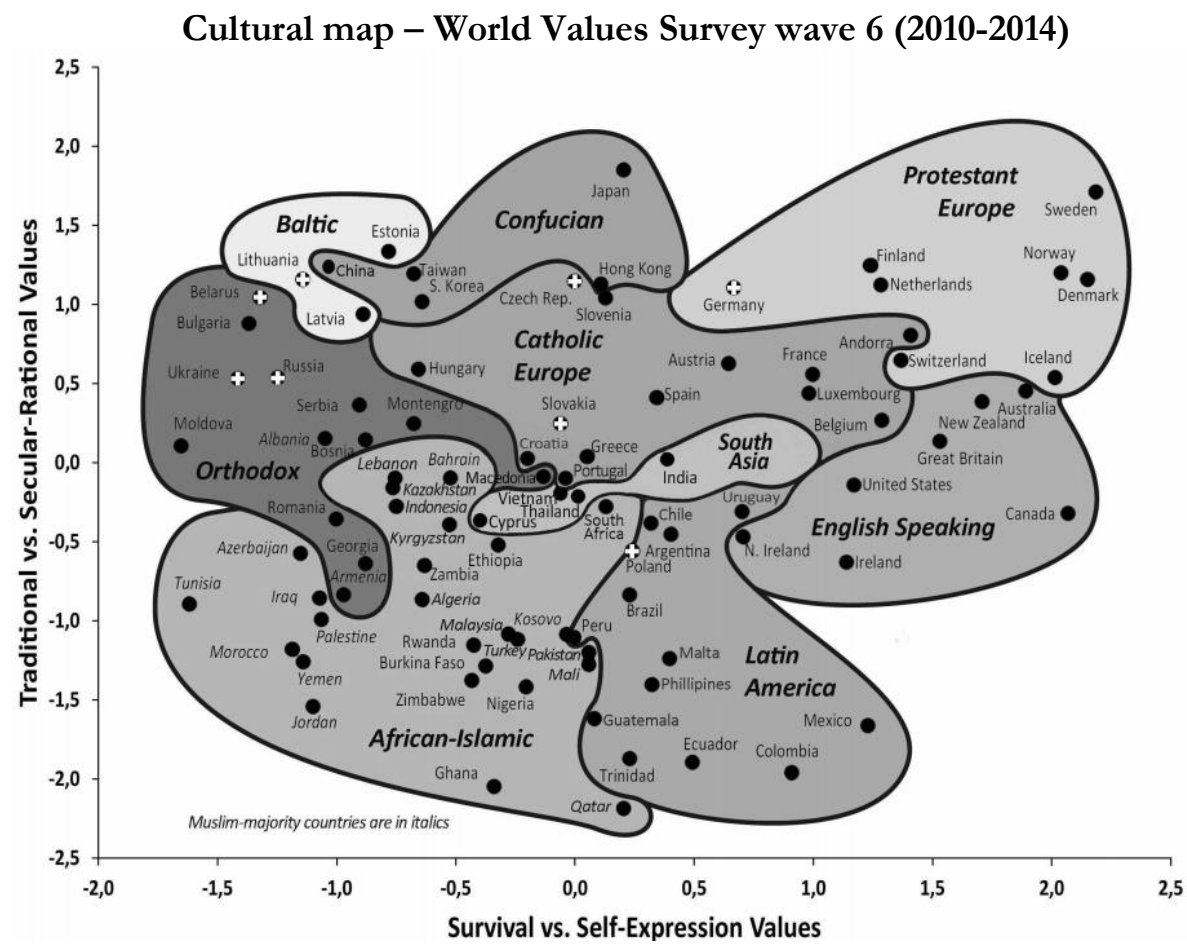

Source: [nglehart, Welzel, 2015]. 
With reference to the Picture 1, we can observe that there are groups of countries which share the same values as evidenced by the proximity of the factor scores. Out of the immediate neighbours of Poland, we clearly distinguish societies in Belarus, Lithuania, Ukraine and Russia which place high emphasis on secular-rational and survival values. In the group of post-communist countries the Czech Republic, Slovakia and Poland share much more self-expression values which prove these societies tend to be more tolerant, trustful, and engage in political and economic activities. Yet they all including Germany (with the exception of Poland which has the most traditional worldview) share very secular values. Moreover, all of them except Germany (a high income country) and Ukraine (a low income country) are middle income countries.

TABLE 1.

Factor scores of values and beliefs by selected countries, WVS waves 1999-2014

\begin{tabular}{|c|c|c|c|c|c|}
\hline \multicolumn{3}{|c|}{ Traditional values versus Secular-rational values } & \multicolumn{3}{|c|}{ Survival values versus Self-expression values } \\
\hline 1999-2004 & 2005-2009 & 2010-2014 & 1999-2004 & 2005-2009 & 2010-2014 \\
\hline \multicolumn{6}{|c|}{ Poland } \\
\hline-0.6 & -0.77 & -0.56 & -0.7 & -0.15 & 0.25 \\
\hline \multicolumn{6}{|c|}{ Germany $^{1}$} \\
\hline 1.05 & 1.35 & 1.1 & 0.42 & 0.66 & 0.68 \\
\hline \multicolumn{6}{|c|}{ The Czech Republic } \\
\hline 1.1 & 1.25 & 1.14 & 0.25 & 0.36 & 0 \\
\hline \multicolumn{6}{|c|}{ Slovakia } \\
\hline 0.5 & 0.67 & 0.25 & -0.5 & -0.4 & -0.07 \\
\hline \multicolumn{6}{|c|}{ Ukraine } \\
\hline 0.77 & 0.3 & 0.54 & -1.77 & -0.84 & -1.42 \\
\hline \multicolumn{6}{|c|}{ Belarus } \\
\hline 0.81 & 0.9 & 1.05 & -1.3 & -1.25 & -1.33 \\
\hline \multicolumn{6}{|c|}{ Lithuania } \\
\hline 0.85 & $--^{2}$ & 1.16 & -1.07 & $--^{3}$ & -1.15 \\
\hline \multicolumn{6}{|c|}{ Russia } \\
\hline 1.0 & 0.5 & 0.54 & -1.9 & -1.4 & -1.25 \\
\hline
\end{tabular}

Note: ${ }^{1}$ refers to Western Germany for years $1999-2004 ;{ }^{2}$ and ${ }^{3}$ no data available for Lithuania for 2005-2009: shading denotes increase in the factor score in the subsequent survey waves.

Source: World Values Survey 1999-2014; Inglehart and Welzel [2015].

Observation of the dynamics in factor scores changes in Table 1 reveals several general trends in the changes of the respective countries' values. The general finding is that as country moves from development country via industrialization to post-industrial knowledge society and its standard of living increases, it tends to move away from the traditional and survival values (the bottom-left corner indicating underdeveloped/poor countries) to towards more secular and self-expression values (the top-right corner indicating developed/rich countries. In terms of the factor scores, it denotes an increase in the $-2.5 / 2.5$ range. The data also confirms general trends implied by the modernization theory which claims that socioeconomic development is linked with coherent and, to 
some extent, predictable changes in culture as well as political life [Inglehart, Welzel 2005 p. 19]. In this respect, the WVS data seems to confirm that main preposition of the theory. Moreover, we can observe that despite the fact that countries move away from traditional and survival vales in favor of secular-rational and self-expression values towards the 'rich' corner, they do tend to remain in the same relative (against each other) position on the value grid and remain in the same country grouping. This certainly is the case with Poland and its neighbouring countries.

Further analysis of the WVS data referring to the views on competition ${ }^{5}$ disclose interesting information. The subsequent waves of the survey demonstrate that less and less share of the populations in Poland and its neighboring countries consider competition unquestionably good (score 1). The same tendency was observed for the other top (2 and 3) scores recording trust in competition. Factually, as time progressed, the countries' populations tended to treat competition with increasing mistrust, as verified by gradually higher shares of 'mistrust in competition' scores (5-2) including the ultimate view that competition is harmful (score 1). This attitude is shared by all the countries in This would suggest that the countries' populations in the region have become much more skeptical and distrustful of competition as a form of market institution.

The two facts carry major implications for the cooperation between countries, Poland and its neighbours in this case. Above all, understanding the fact that the cultural capital and shared values make an important factor of socio-economic development which cannot be disregarded in the international and economic policy planning. Furthermore, as Poland and its neighbouring countries continue to enjoy socio-economic development and increase their standard of living, they should make use of the common pool of values as their cultural capital in order to gain comparative advantage while dealing with other countries of the world. In the globalized world, where it is important to use all possible resources, the cultural capital of common worldviews and values is not to be missed out on particularly with regard to international cooperation. Under these conditions, shared values and culture can render a direct market value for cooperating countries, otherwise progressively more biased against competition, and let hitherto geographical and cultural clusters of developing regions capture their share of the global economic growth.

\footnotetext{
5 The WVS question wording was: Now I would like you to tell me your views on various issues. How would you place your views on this scale? 1 means you agree completely with the statement on the left; 10 means you agree completely with the statement on the right; and if your views fall somewhere in between, you can choose any number in between. Statement 1: Competition is good. It stimulates people to work hard and develop new ideas. Statement 2: Competition is barmful. It brings out the worst in people. The question had its equivalences in the following waves of WVS: 1990/1994: V254; 1995/1999: V128; 2000/2004: V144; 2005/2009: V119; 2010/2013: V99. Unfortunately, the survey did not examine the notion of cooperation; alternatively, it did cover the idea of helpfulness (Q: It is important to this person to help the people nearby? WVS 2010-2014: A193), yet its relevance to the study was limited as the question was asked in the sixth wave of the survey only (with the exception of Germany, which also answered an equivalence in the following WVS wave). The data generally reveals a shared tendency to help by majority of the societies but we are unable to trace the trend in the past. Moreover, the last the 2010-2014 WVS wave excluded Belarus, Lithuania, the Czech Republic and Slovakia.
} 


\section{Conclusions}

Despite the enormous benefits of competition, excessive reliance on it has largely contributed to dehumanization of the market economy. Yet market is not only about competing but it is also about cooperation. This feature has been forgotten for the most part in the midst of quantitative analyses, mathematical modeling, and profit maximization. The financial crisis in the last decade proved that unwarranted competition with no regard to values, where there is little room for sustainable cooperation between market participants actually hurts economy. At the same time cooperation provides new opportunities and can potentially help the global economy; in these conditions the developing countries' economies develop more sustainably. After all, the very idea of sustainable development rests on cooperation between people and coordination of activities in different spheres of life. Certainly that is not supposed to mean that market should all of a sudden shed its competitive traits. Yet cooperation and competition do complete each other. This becomes particularly evident in the context of culture and values shared by societies. Recognition of culture as another important element of economic analysis has helped to emphasize the role of cooperation and relationships for economic development at the expense of competition and profit maximization. Yet the most important is the fact that culture and values (particularly when shared among the system participants) can potentially enhance cooperation, which is of crucial importance for regional/international development. Analysis of the values in societies of Poland and its neighbouring countries based on the results of the World Values Survey demonstrates that despite the changes in the prevailing worldviews of their citizens they do continue to share most of their values, including increasing distrust of competition. In this sense, a better mutual understanding of our neighbouring countries cultures and values plays a critical role in stimulating and promoting mutual cooperation. On the one hand, it constitutes a significant economic resource and a source of comparative advantage, which becomes particularly critical in the context of competition in the world markets. On the other hand and above all, however, we primarily need cooperation, not competition; values, not prices; culture, not profits in order to make the world a better place for ourselves and future generations. These considerations are also of utmost importance in the context of the role of Poland in the socio-economic development of this part of the world.

\section{Literature}

Atalik G., Fischer M. M. (eds.) 2002 Regional Development Reconsidered, Springer-Verlag, Berlin, DOI 10.1007/978-3-642-56194-8.

Axelrod R., Hamilton W. D. 1981 The Evolution of Cooperation "Science, New Series" Vol. 211, No. 4489, pp. 1390-1396.

Banfield E. 1958 The Moral Basis of a Backward Society, Free Press, New York.

Boaz D. 2011 Competition and Cooperation, [in:] The Morality of Capitalism, T. G. Palmer (ed.), Jameson Books, Inc., Ottawa, Illinois. 
Boulding K. E. 1972 Toward the Development of a Cultural Economics, "Social Science Quarterly", Vol. 53, No. 2 pp. 267-284.

Branderburger A. M., Nalebuff B. J. 1996 Coopetition, Currency Doubleday, New York.

Chartrand H. H. 1990 The Hard Facts: Perspectives of Cultural Economics [in:] Transactions of the Royal Society of Canada 1989, Fifth Series, Vol. IV, University of Toronto Press, Toronto.

Coleman J. S. 1990 Foundations of Social Theory, Harvard University Press, Cambridge, MA.

Collins English Dictionary, Third edition 1991.

Deutsch M. 2011 Cooperation and Competition [in:] Conflict, Interdependence, and Justice. (ed.) P. T. Coleman, Springer, New York, DOI 10.1007/978-1-4419-9994-8_2.

Fischer M. M. 2002 A Systemic Approach to Innovation [in:] Regional Development Reconsidered (eds.) Atalik G., Fischer M. M., Springer-Verlag, Berlin.

Fukuyama F. 1995 Trust: The Social Virtues and the Creation of Prosperity, Free Press, New York.

Guiso L., Sapienza P., Zingales L. 2006 Does Culture Affect Economic Outcomes? "Journal of Economic Perspectives" Vol. 20, No. 2 pp. 23-48.

Harrison L. E., Huntington S. P. (eds.) 2000 Culture Matters: How Values Shape Human Progress, Basic Books, New York.

Hofstede G. 1991 Cultures and Organizations: Software of the Mind, McGraw-Hill, London.

Ims, K. J., Jakobsen O. D. 2010 Competition or Cooperation? A Required Shift in the Metaphysics of Economics [in:] The Collaborative Enterprise: Creating V alues for a Sustainable World (eds.) A. Tencati, L. Zsolnai, Peter Lang, Oxford.

Inglehart R., Welzel C. 2005 Modernization, Cultural Change, and Democracy. The Human Development Sequence, Cambridge University Press. Cambridge

Inglehart R., Welzel C. 2015 World Values Survey. Findings and Insights, accessed at [www.worldvaluessurvey.org/WVSContents.jsp on 14.05.2015]

Kim Y. J., Lee C. 2015 Social values and economic dynamics "Journal of Economic Dynamics \& Control" 53 (2015) pp. 69-84.

Landes D. 1998 The Wealth and Poverty of Nations. Why Some Are So Rich and Some So Poor, Norton \& Company Inc., New York.

North D. C. 1990 Institutions, Institutional Change and Economic Performance, Cambridge University Press, Cambridge.

Nowak M. 2012 Why We Help "Scientific American” Vol. 307, Issue 1, pp. 34-39.

Nozick R. 1974 Anarchy, State, and Utopia, Blackwell Publishers, Oxford.

Patchell J. 1996 Kaleidoscope Economies: The Process of Cooperation, Competition, and Control in Regional Economic Development "Annals of the Association of American Geographers" 86(3), pp. 481-506.

Porter M. E., Kramer M. R. 2011 Creating Shared Value "Harvard Business Review, Vol. 89 Issue 1/2 pp. 62-77.

Putnam R. 1993 Making Democracy Work, Princeton University Press, Princeton, N.J.

Rubin P. H. 2014 Emporiophobia (Fear of Markets): Cooperation or Competition? "Southern Economic Journal” 80(4), pp. 875-889. 
Smith A. 1776 An Inquiry into the Nature and Causes of The Wealth of Nations, J. B. Wight (ed.), Harriman House, Petersfield, Hampshire (2007).

Smith A. 1759 The Theory of Moral Sentiments (ed.) K. Haakonssen, Cambridge University Press, Cambridge (2002).

Smith V. L. 1998 The Two Faces of Adam Smith, "Southern Economic Journal", Vol. 65, No. 1 (Jul., 1998) pp. 2-19.

Soros G. 1997 The Capitalist Threat "The Atlantic Monthly", February 1997, Vol. 279, No. 2, pp. 45-58

Taylor T. 2015 The Blurry Line Between Competition and Cooperation, accessed at [http://www.econlib.org/library/Columns/y2015/Taylorcompetition.html\# on 5.05.2015]

Trompenaars F., Hampden-Turner C. 1998 Riding the Waves of Culture: Understanding Cultural Diversity in Business, Nicholas Brealey Publishing, London.

Tyler T. R. 2011 Why People Cooperate. The Role of Social Motivations, Princeton University Press, Princeton.

Voss, J. 2012 Capitalism: It's as Much About Cooperation as Competition "Enterprising Investor" 16 July 2012, accessed at [http://blogs.cfainstitute.org/investor/2012/ 07/16/capitalism-it-is-as-much-about-cooperation-as-competition/, on 5.05.2015]

Wilkin J. 1997 Efektywność a sprawiedliwosí jako problem ekonomiczny [in:] Efektywność a sprawiedliwość, (ed.) J. Wilkin, Key Text, Warszawa.

Wimmer A. 2013 Ethnic Boundary Making: Institutions, Power, Networks, Oxford University Press, New York.

World Values Survey 1999-2014 Online Data Analysis, accessed at [www.worldvaluessurvey.org/WVSOnline.jsp on 6.01.2016] 